\title{
What to do with female drug-using offenders?
}

\author{
Keith J. B. Rix
}

\section{COMMENTARY ON... COCHRANE CORNER ${ }^{\dagger}$}

\begin{abstract}
SUMMARY
Female drug-using offenders are a large but under-researched and vulnerable population with specific needs. Only a handful of randomised controlled trials of interventions for this population are of sufficient quality to shed light on what might work to reduce their criminal activity and drug use, and interpretation of the results of most of these trials is limited by an 'unclear' risk of bias due to a lack of descriptive information. Better-quality research is needed to inform practitioners and policy makers. In the meantime, this month's Cochrane Corner review provides cautious support for the use of some psychosocial treatments, particularly if delivered in a gender-responsive way addressing issues of abuse and victimisation, in the expectation that re-imprisonment can be prevented, even if there is no proven effect on re-arrest rates and only uncertain effects on substance use.
\end{abstract}

\section{DECLARATION OF INTEREST}

None

'For the last two years, the female prison population has been consistently under 4,000 for the first time in a decade. I want to see still fewer women in custody, especially those who are primary carers of young children.' - Caroline Dinenage MP, Parliamentary Under Secretary of State for Women, Equalities and Family Justice (Dinenage 2015).

'We want to see more effective provision for women offenders, making it possible for there to be a substantial fall in the women's prison population in the coming months and years.' - House of Commons Justice Committee (2015: p. 16).

'The number of women offenders is comparatively small but the impact is not and it is obvious that within the criminal justice system we cannot simply replicate what we provide for men and hope it will work for women.' - David Ford MLA, Northern Ireland Minister of Justice (Prison Reform Trust 2015).

According to the charity Women in Prison (2015) there were 3935 women imprisoned in England and Wales on 13 July 2015, and the average cost of keeping a woman in prison for a year is $£ 44329$ (Ministry of Justice 2014a). The charity reports that almost half of women prisoners have suffered domestic violence and just over half have suffered emotional, physical or sexual abuse in childhood. It reports that more than half admit to having used cocaine, crack cocaine or heroin in the 4 weeks prior to imprisonment, and an earlier study (Plugge 2006) found that $75 \%$ of women prisoners had used drugs in the 6 months prior to imprisonment. The charity reports that at least one-fifth of women prisoners were lone parents before imprisonment and it quotes an estimate that in 2010 more than 17240 children were separated from their mothers by imprisonment.

Women prisoners represent only a fraction of women offenders. Only 15\% of women sentenced for indictable offences receive an immediate custodial sentence, and each year there are nearly 200000 prosecutions of women for non-motoring summary (non-indictable) offences (Ministry of Justice 2014b), for which the majority receive a non-custodial sentence. So, women in prison are only the tip of the iceberg of female offending.

Given the size of the problem, not just in terms of the resources of the criminal courts and the cost to the prison estate, but most importantly in terms of the impact of drug use and offending on the health and well-being of the women themselves and on their partners and children, it is enormously disappointing that since Perry et al's previous review (Perry 2006) there has been so little research of a sufficiently high quality. ${ }^{\text {a }}$ As Corston (2007) observed, female offenders represent an under-researched, vulnerable population with specific needs distinct from their male counterparts. Although the authors' latest review (Perry 2015), the summary of which appears in this month's Cochrane Corner, has identified a number of randomised controlled trials (RCTs) of interventions for female drugusing offenders published since 2006, none has been of high quality.

Out of more than 10000 reports identified, the 2015 review is based on only 9 of the 72 empirical studies that made it to Phase II screening. Out of the 9 studies, the majority were rated as being at
ROUND THE CORNER
Keith Rix is an honorary consultant forensic psychiatrist, Norfolk and Suffolk NHS Foundation Trust, and Visiting Professor of Medical Jurisprudence, University of Chester, where he is involved with its MSc in Medicolegal Practice. He is an elected Honorary Fellow of the Faculty of Forensic and Legal Medicine of the Royal College of Physicians. Correspondence Professor Keith J. B. Rix, The Fermoy Unit, Queen Elizabeth Hospital, Gayton Road, King's Lynn PE30 4ET, UK. Email: keith.rix@nsft.nhs.uk

${ }^{\dagger}$ See p. 358, this issue.

a. Cochrane reviewers assess the quality of evidence using the Grading of Recommendations Assessment, Development and Evaluation (GRADE) system (www. gradeworkinggroup.org). 
unclear risk of bias due to a lack of descriptive information, and they yielded only low- or moderate-quality evidence at the most. It is also disappointing that there were too few studies to evaluate whether the treatment setting, for example, court or community, had an impact on success. It is important to know whether efforts should be focused on women appearing before the courts or on those imprisoned. It is also disappointing that none of the studies provided evidence as to cost-effectiveness.

\section{The review}

Perry et al (2015) identified and reviewed 9 RCTs of interventions that were designed, wholly or in part, to eliminate or prevent relapse to drug use or criminal activity among women referred by the criminal justice system at baseline and for whom the study reported pre- and post-programme measures of drug use and criminal behaviour and the same length of follow-up for the two groups. Box 1 shows the experimental interventions included in the review.

The results of the 9 eligible trials were published between 1996 and 2014. Eight of them were from the USA and one was from Spain. The average age of the participants was in the early- to mid-30s. According to the review's authors, in all but one study the participants were of White ethnic origin, but this seems to be an erroneous or misleading observation, as in 5 studies the percentage of what the Cochrane reviewers term 'non-White' participants was more than $50 \%$.

\section{Does psychosocial intervention make any difference?}

Five studies permitted a comparison of any psychosocial intervention with treatment as usual.

Two examined drug use. Johnson et al (2011) found no effect. Lanza et al (2014), in a study comparing cognitive-behavioural therapy (CBT) with acceptance commitment therapy (ACT) (Box 2) and a control intervention, found no effect of the CBT on the abstinence level, but an abstinence level of $44 \%$ following ACT, compared with $18 \%$ in the control group.

Two studies (Nielsen 1996; Guydish 2011) examined re-arrest rates and found no difference between interventions. However, three (Nielsen 1996; Zlotnick 2009; Johnson 2011), albeit only with moderate-quality evidence, found a reduction in imprisonment (effect size 0.46). Box 3 shows the psychosocial interventions that reduced imprisonment.

These results appear a little less disappointing when the nature of the control intervention is

\section{B0X 1 Experimental interventions included in the review}

- Any pharmacological intervention (e.g. buprenorphine, methadone)

- Any psychosocial intervention (e.g. therapeutic community, case management, cognitive-behavioural therapy, interpersonal psychotherapy, motivational interviewing

taken into account. 'Treatment as usual' is not 'no treatment' or 'no intervention'. The comparison by Johnson et al (2011) of community collaborative behavioural management was with standard parole supervision in the form of 1-4 contacts a month with a parole officer, who was affiliated to a substance misuse treatment programme, and drug testing. The control intervention employed by Lanza et al (2014) was a mental health assessment and a re-education programme. Nielsen et al (1996) used as a control intervention Delaware's 6-month conventional work-release programme and this was a low-quality study. Zlotnick et al (2009) employed a 'standard therapy' control intervention (Box 3) comprising a substance use treatment programme that included group and individual casework delivered over a number of months and dealing comprehensively with a variety of issues pertinent to female offenders.

The only trial that found no benefit for the trial intervention compared with treatment as usual was that of Guydish et al (2011), who simply compared intensive probation case management, which included therapeutic and advocacy orientation and training, with standard probation. But this was a low-quality study and, as has been observed elsewhere (Sorenson 2003), although probation case management is designed to be more engaging than standard probation, there is a low level of face-to-face contact.

BOX 2 Acceptance commitment therapy

- 16 weekly group sessions of 90 minutes led by a trained therapist

- Seeks to undermine the grip of the literal verbal content of cognition that provokes avoidance behaviour and to construct an alternative context in which behaviour aligned with one's values is more likely to occur

- Aims to increase substance use abstinence

- Sessions involve experiential and didactic learning

- Employs validation and empowerment to help participants respond to previously avoided events in new ways 


\section{Pharmacological treatment}

There was a single study of pharmacological treatment (buprenorphine) (Cropsey 2011). Although it prevented or delayed relapse to opioid use during the treatment phase, the results were not sustained post-treatment and most women had relapsed into active opioid use at the 3-month follow-up point.

\section{The nature of the psychosocial treatment}

Four studies compared different psychosocial interventions. Johnson et al (2011) found interpersonal psychotherapy superior to psychoeducational attention in reducing levels of depression and substance misuse in women with major depression. Lanza et al (2014) failed to demonstrate an effect of CBT but, as indicated above, did find an effect of ACT in terms of abstinence. Messina et al (2010) compared a gender-responsive therapeutic community programme with a standard therapeutic community programme and found that the gender-responsive treatment had a greater effect in terms of both subsequent drug use and re-imprisonment. The components of the genderresponsive treatment are shown in Box 4.

Sacks et al (2008) found that both therapeutic community intervention and the CBT control intervention resulted in improvements in mental health, substance misuse, criminal behaviour and HIV risk.

\section{Cost and cost-effectiveness}

None of the studies included any cost information, so it was not possible to examine the costeffectiveness of the interventions.

\section{So what?}

As none of the reviewed studies was of more than moderate GRADE quality, by definition further research is likely, if not very likely, to have an important impact on the confidence in the estimates of the effects of the treatments and may, or even is likely to, change the estimate. The implication of this review for researchers is that 'high quality research is required to evaluate the effectiveness of different treatment options for female drug-using offenders' (Perry 2015). Of particular value would be trials of some of the interventions employed in these studies with greater attention to overcoming the obstacles, and avoiding the pitfalls, that reduced their quality and gave rise to concerns about reporting bias.

What are the implications for practitioners and policy makers? The review provides cautious support for incorporating psychosocial treatment approaches - such as elements of therapeutic community treatment, interpersonal

B0X 3 Psychosocial interventions that reduced imprisonment

Collaborative behavioural management (Johnson 2011)

12-week intervention

Treatment sessions with offender, officer and substance use counsellor at least every 2 weeks, plus further officer/offender contacts Premise: reinforcing desired behaviour is more likely to result in sustained positive change than punishing undesired behaviour

Intensive work release (Nielsen 1996)

'Continual Recovery through Education and Skills Training' (CREST):

- Therapeutic community programme

- 1 month orientation, 2 months primary treatment, 3 months work release

Cognitive-behavioural therapy combined with standard therapy (Zlotnick 2009)

Cognitive-behavioural therapy - 'Seeking Safety' programme:

- development of coping skills to attain safety from post-traumatic stress disorder and substance use disorders
- focus on the present

- abstinence oriented

- emphasis on empowering, compassionate approach

- group modality, 90 minutes, typically 3 times a week for $6-8$ weeks

- 3-5 women per group

- optional weekly booster session for 12 weeks after release

Standard therapy - substance misuse treatment programme:

- abstinence oriented

- psychoeducational large-group format

- weekly individual case management and drug counselling

- attention to women's health, domestic violence, affect management, relapse prevention, career exploration, anger management, parenting

- no specific trauma treatment

- referral for further substance misuse treatment on release

\section{B0X 4 Gender-responsive treatment}

\begin{tabular}{lc}
\hline Therapies & - Reviewing the histories of their \\
Cognitive-behavioural approaches, & relationships \\
mindfulness meditation, experiential & - Considering how they can build healthy \\
therapies (guided imagery, visualisation, & support systems \\
art therapy, movement), psychoeducational, & Sexuality module \\
relational and expressive arts techniques & - Exploring the connections between \\
'Helping Women Recover' - 17-session & addictions and sexuality, and \\
programme with 4 modules & discuss body image, sexual identity, \\
Self module & sexual abuse and the fear of sex \\
- Discovering what the 'self' is & when sober \\
- Learning that addiction can be & Spirituality module \\
understood as a disorder of the self & - Introduction to the concepts of \\
- Learning the sources of self-esteem & spirituality, prayer and meditation \\
- Considering the effects of sexism, & 'Beyond Trauma' - 11 sessions focused \\
racism and stigma on a sense of self & on 3 areas \\
Relationship module & - Teaching women what abuse and \\
- Women explore their roles in their & trauma are \\
families of origin & - Helping them to understand what \\
- Discussing myths and realities about & typical reactions to trauma and abuse \\
motherhood and their relationships with & are \\
their mothers & - Developing coping skills
\end{tabular}


the role that trauma and abuse play in the lives of these women. However, expectations need to be modest: there may be little or no effect on drug use and arrest rates. But even a small reduction in the numbers of women imprisoned makes the work worthwhile, albeit that the cost is unknown.

\section{References}

Corston J (2007) The Corston Report: A Report by Baroness Jean Corston of a Review of Women with Particular Vulnerabilities in the Criminal Justice System. Home Office.

Cropsey KL, Lane PS, Hale GJ, et al (2011) Results of a pilot randomized controlled trial of buprenorphine for opioid dependent women in the criminal justice system. Drug and Alcohol Dependence, 119: 172-8.

Dinenage C (2015) Appendix: Government response. In Justice - First Special Report. Women Offenders: Follow-Up. House of Commons (www.publications.parliament.uk/pa/cm201516/cmselect/ cmjustice/374/37404.htm).

Guydish J, Chan M, Bostrom A, et al (2011) A randomized trial of probation case management for drug-involved women offenders. Crime and Delinquency, 57: 167-98.

House of Commons Justice Committee (2015) Women Offenders: Follow-Up. Thirteenth Report of Session 2014-15 (HC 314). TSO (The Stationery Office)

Johnson JE, Friedmann PD, Green TC, et al (2011) Gender and treatment response in substance use treatment-mandated parolees. Journal of Substance Abuse Treatment, 40: 313-21.

Lanza PV, García PF, Lamelas FR, et al (2014) Acceptance and commitment therapy versus cognitive behavioral therapy in the treatment of substance use disorder with incarcerated women. Journal of Clinical Psychology, 70: 1-14.

Messina N, Grella CE, Cartier J, et al (2010) A randomized experimental study of gender-responsive substance abused treatment for women in prison. Journal of Substance Abuse Treatment, 38: 97-107.
Ministry of Justice (2014a) Costs per Place and Costs per Prisoner: National Offender Management Service Annual Report and Accounts 2013-14 Management Information Addendum. Ministry of Justice.

Ministry of Justice (2014b) Statistics on Women and the Criminal Justice System 2013: A Ministry of Justice Publication under Section 95 of the Criminal Justice Act 1991. Ministry of Justice.

Nielsen AL, Scarpitti FR, Inciardi JA (1996) Integrating therapeutic community and work release for drug-involved offenders: the CREST Program. Journal of Substance Abuse Treatment, 13: 349-58.

Perry A, Coulton S, Glanville J, et al (2006) Interventions for drug-using offenders in the courts, secure establishments and the community. Cochrane Database of Systematic Reviews, 3: CD005193.

Perry AE, Neilson M, Martyn-St James M, et al (2015) Interventions for female drug-using offenders. Cochrane Database of Systematic Reviews, 6: CD010910.

Plugge E, Douglas N, Fitzpatrick R (2006) The Health of Women in Prison: Study Findings. Department of Public Health, University of Oxford.

Prison Reform Trust (2015) Why Focus on Reducing Women's Imprisonment? PRT (http://www.prisonreformtrust.org.uk/Portals/0/ Documents/why\%20).

Sacks JY, Sacks S, McKendrick K, et al (2008) Prison therapeutic community treatment for female offenders: profiles and preliminary findings for mental health and other variables (crime, substance use and HIV risk). Journal of Offender Rehabilitation, 46: 233-61.

Sorenson JL, Dilley J, London J, et al (2003) Case management for substance abusers with HIV/AIDS: a randomized clinical trial. American Journal of Drug and Alcohol Abuse, 29: 133-50.

Women in Prison (2015) Key facts. Women in Prison (http://www. womeninprison.org.uk/research/key-facts.php). Accessed 18 October 2016.

Zlotnick C, Johnson J, Najavits LM (2009) Randomized controlled pilot study of cognitive-behavioural therapy in a sample of incarcerated women with substance use disorder and PTSD. Behavior Therapy, 40: $325-36$ 